\title{
Flexible Reflective Color Displays using Thermochromic Pigments
}

\author{
Kyong Chan Heo', Youngku Sohn ${ }^{2}$, Jonghoon Yi ${ }^{1}$, Jin Hyuk Kwon ${ }^{1}$, and Jin Seog Gwag ${ }^{1}$ * \\ ${ }^{1}$ Department of Physics, Yeungnam University, 214-1 Dae-dong, Gyeongsan 712-749, Korea \\ ${ }^{2}$ Department of Chemistry, Yeungnam University, 214-1 Dae-dong, Gyeongsan 712-749, Korea
}

(Received July 31, 2013 : accepted September 17, 2013)

\begin{abstract}
This research presents a flexible reflective thermochromic display (TCD) comprised of thermochromic pigments and a patterned indium tin oxide (ITO) film coated on a polyethylene naphthalate (PEN) substrate, and the display's thermo-optical characteristics. The display showed maximum red, green, and blue reflectances of $30 \%, 38 \%$, and $29 \%$, respectively. Furthermore, the display exhibited a continuous grey color when the temperature was changed continuously. As a flexible display, the display showed reliable thermo-optical performance without image damage even when highly bent. We expect the proposed TCD will be used in outdoor information display applications where low cost is a key factor.
\end{abstract}

Keywords : Thermochromic display, Reflective display, Flexible display, Thermochromic pigmnet OCIS codes : (160.6840) Thermo-optical materials; (120.2040) Displays; (130.0250) Optoelectronics

\section{INTRODUCTION}

Reflective flexible displays have received enormous attention owing to their light weights, bendabilities, portabilities, and readabilities in sunlight. These displays have potential usages as next generation displays in applications, such as, wearable displays, paper-like displays, smart cards, large area sensors, and actuators.

Reflective liquid crystal displays (LCDs) [1-3] and electrophorectic displays (EPD) [4] have been studied for mobile devices, outdoor poster displays, and e-books. Although the technologies of conventional displays, based on LCDs and organic light emitting diodes (OLEDs), are promising for flexible display applications, they require expensive, complex manufacturing processes. On the other hand, the reflective thermochromic display fabrication process is cheaper than those of conventional electron-based devices.

Thermochromic materials have attracted great attention in the chemical, biochemical, and applied research areas, because their colors and optical properties depend on external stimuli, such as, heat and mechanical stress, and ligand interactions [5-9]. Applications for such materials include reflective thermochromic displays, temperature sensors, and color filters [10, 11].

Recently, a thermally actuated display using mono-color thermochromic polymer and a silver polydimethelysiloxane (PDMS) conductive wiring pattern was reported by Liu et al. [5]. The thermochromic polymer used changed from dark green to white above $60^{\circ} \mathrm{C}$. O. Yarimaga et. al. [8] reported a conjugated polydiacetylene-based multicolor thermochromic display (TCD) that changed color continuously from blue to red as a function of temperature. The red color was achieved at $75^{\circ} \mathrm{C}$ and a yellow-green color was activated at $180^{\circ} \mathrm{C}$, which is high for a display that requires a fast response time, low power consumption, and safe operation. Regarding fabrication, design, and the optimization of thermo-optical properties, color reversibility and the color transition temperatures of thermochromic materials are key considerations [5-7]. However, despite much research on TCD, few reports have been issued on multicolor displays and outdoor information display applications [12].

Thermochromism of organic dyes and inorganic materials (e.g. fluorans, spiropyrans, and luceo dyes) has generally occurred due to rearrangement of molecular structure (e.g., ring opening/closure and tautomeric rearrangement), and an intercalation/de-intercalation effect, respectively [13]. The three thermochromic pigments considered in this paper generate color transitions at $38^{\circ} \mathrm{C}$, which is acceptable in terms of achieving low power consumption. Furthermore, the maximum contrast ratio (CR) of our thermochromic display is twice that reported by O. Yarimaga et al. for a

\footnotetext{
*Corresponding author: sweat3000@ynu.ac.kr

Color versions of one or more of the figures in this paper are available online.
} 
polydiacetylene (PDA)-based multicolor thermochromic display [12]. Because a polyethylene naphthalate (PEN) is used as a flexible substrate, our display could be easily adapted for use in various environments.

We have reported results of the multicolor-TCD cells for information display application based on a glass substrate [14]. Here, we want to extend thermochromic application as it is applicable to flexible multicolor display which is highlighted as a next generation display. We present a simple, flexible, reflective multicolor thermochromic display based on a PEN substrate coated with an indium tin oxide (ITO) film. In addition, the optical properties of this thermochromic display were investigated to examine its potential as a TCD cell for information displays.

\section{EXPERIMENTS}

The three different colored thermochromic pigments were provided by H.W. Sands Corp., a chromic company of American [15]. The accurate chemical compositions of the thermochromic pigments obtained from H.W. Sands Corp. are unknown (proprietary information), but are presumably similar to other formulations reported in the literature $[16,17]$. The thermochromic material used in the study is believed to be vinyl acrylate terpolymer-type with an additive, where the additive reversibly interacts with the polymer with temperature to result in change in color. The pigments consist of microcapsules that turn color reversibly with changes in temperature. The color transition temperatures of pigments range from $-10^{\circ} \mathrm{C}$ to $69^{\circ} \mathrm{C}$, precise control transition temperature is achieved by using different pigment compositions [17].

In this work, the thermochromic display devised consisted of a non-thermochromic pigment and thermochromic pigments on patterned indium tin oxide (ITO)-sputtered polyethylene naphthalate (PEN) film (Fig. 1). The ITO-heater array was (a)

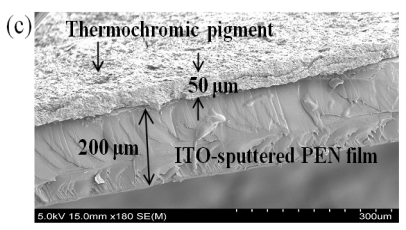

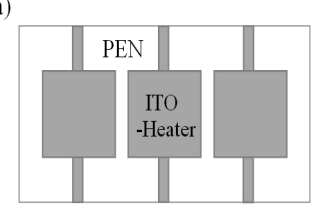

(b) Thermochromic Non-thermochromic
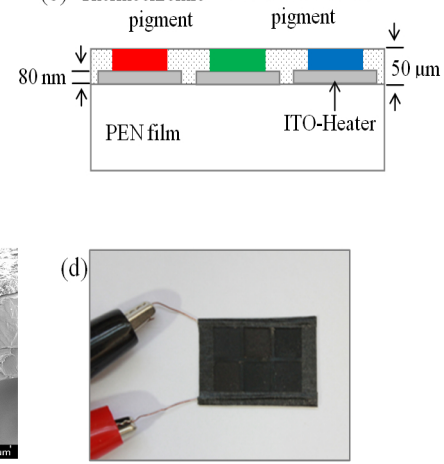

FIG. 1. (a) Schematic of the patterned ITO-heater array on polyethylene naphthalate (PEN) substrate (b) Cross-sectional schematic of the device (c) SEM image of the display showing the PEN substrate, the IN TERMS of heater, and the thermochromic pigment. (d) fabricated thermochromic display cell. designed to be $5 \times 5 \mathrm{~mm}^{2}$ with $1 \mathrm{~mm}$ between adjacent cells (Fig. 1(a) and (b)). Figure 1(b) shows a crosssectional schematic of fabricated display cell. This spacing enables heat isolation between cells. Pigments were selected that were black at room temperature and red, green, or blue at $38^{\circ} \mathrm{C}$. The particle sizes of the microcapsulated thermochromic pigments were such that $97 \%$ of particles were $<6 \mu \mathrm{m}$. Reversible thermochromic pigments are usually a mixture of conventional dyes and pigments. The thermochromic effect is generally observed by a change from a colored to a colorless state on increasing temperature.

The thermochromic display (TCD) cell was fabricated as follows. Indium tin oxide (ITO) films were deposited on polyethylene naphthalate (PEN) at $100^{\circ} \mathrm{C}$ for 40 minutes by $\mathrm{RF}$ magnetron sputtering using an indium tin alloy target composed of $\mathrm{In} 2 \mathrm{O} 3(90 \mathrm{wt} \%)$ containing $\mathrm{SnO}_{2}(10$ wt\%)., All substrates were briefly cleaned ultrasonically with ethanol and distilled water, and dried on a hot plate at $100^{\circ} \mathrm{C}$ for 5 minutes. Deposition was performed in 20 sccm of flowing Ar under mass flow-meter control. The working and base pressures of the sputtering system were $8 \times 10^{-4}$ Torr and $5 \times 10^{-6}$ Torr, respectively. The RF power applied throughout ITO deposition was $15 \mathrm{~W}$. Deposition was carried out at $100^{\circ} \mathrm{C}$ for 40 minutes to provide roughly $80 \mathrm{~nm}$ thick ITO films. The electrical resistivity of the ITO-sputtered PEN film was approximately $3.0 \times 10^{-3}$ $\Omega \cdot \mathrm{cm}$. Because the heating material is an ITO conductor with appropriate resistance, temperature is tunable by adjusting the electrical current. The red thermochromic pigment was deposited on the ITO heater by spraying onto a patterned mask, and pigment was then dried for 10 minutes at $23^{\circ} \mathrm{C}$. Subsequently, the patterned mask was shifted to the next pixel and the green thermochromic pigment was administered and dried in the same manner. Blue thermochromic pigment was deposited in the same manner. All pigment layers were roughly $50 \mu \mathrm{m}$ thick as shown in Fig. 1(c) which is a scanning electron microscopic (SEM) image taken to check the real cross sectional dimension of each layer. Figure 1(d) shows the fabricated thermochromic display cell. Spectral reflectance was measured as a function of the applied voltage using a Cary 5000 UV-VIS-NIR spectrophotometer (Agilent-Korea).

\section{RESULTS AND DISCUSSION}

We activated the reflective thermochromic display (TCD) cells by increasing applied voltage that can drive current in the cell, which enhances temperature by Joule heating. Experiments were carried out at room temperature $\left(23^{\circ} \mathrm{C}\right)$. We also measured the temperature of the center surface of the display cell under steady state conditions using a thermocouple.

Figure 2 shows the temperatures obtained by applied voltage and pixel images of the TCD when the applied voltage was increased from $0 \mathrm{~V}\left(23^{\circ} \mathrm{C}\right)$ to $6 \mathrm{~V}\left(65^{\circ} \mathrm{C}\right)$. Figure 2(a) presents temperature versus applied voltage 


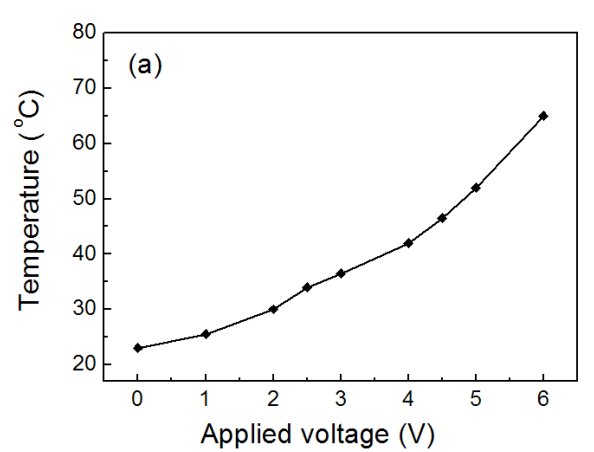

(b)

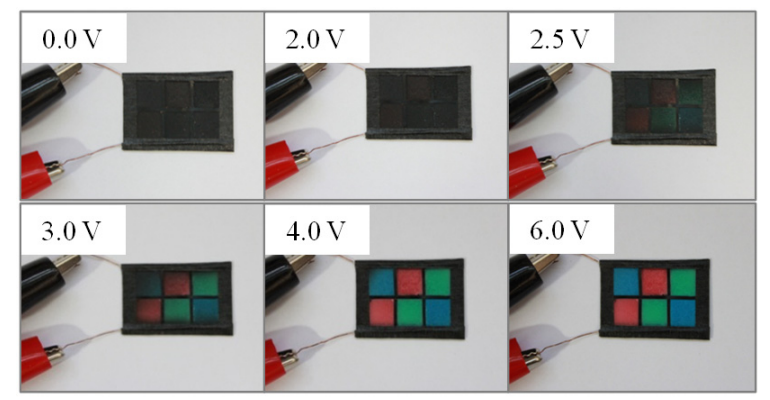

FIG. 2. (a) Characterization of the temperature with applied voltage and (b) photo images of the display cells when the applied voltage was changed from 0 to $6 \mathrm{~V}$.

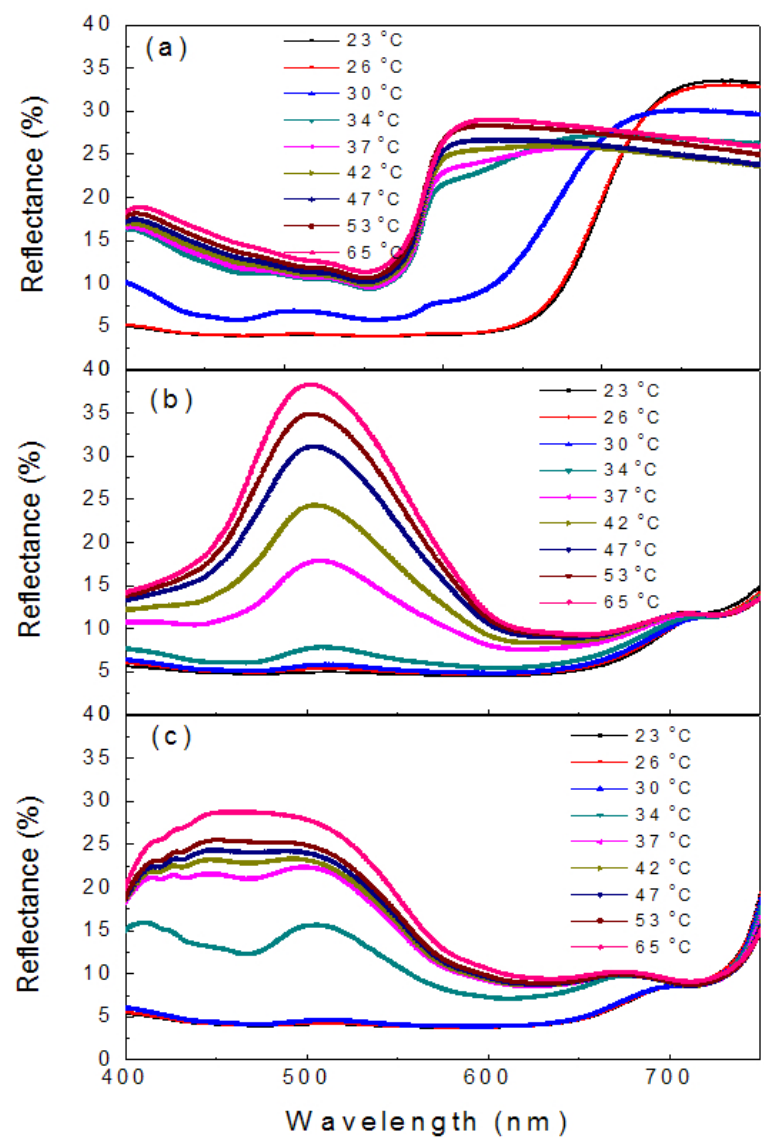

FIG. 3. Temperature dependent reflectance spectra to the thermochromic display cells coated with three different thermochromic pigments. curves. The display cell was black at below $2.0 \mathrm{~V}$, as shown in Fig. 2(b), but this changed to red, green, and blue by applying a voltage above $4 \mathrm{~V}$. Increasing the applied voltage decreased the time taken to induce the color change (at $42^{\circ} \mathrm{C}$ ). As shown in Fig. 2, the temperatures achieved were homogeneously distributed between electrodes. Furthermore, the continuous color changes mean that various colors can be obtained by mixing the red and green, and blue grey.

To confirm various gray levels, we measured spectra reflectances at different temperatures (Fig. 3) Figure 3 shows variations of reflectance spectra versus temperature for TCD cells coated with three thermochromic pigments. Red (at $650 \mathrm{~nm}$ of Fig. 3(a)), green (at $510 \mathrm{~nm}$ of Fig. 3(b)) and blue ((at $475 \mathrm{~nm}$ of Fig. 3(c)) reflectances were increased by $30 \%, 38 \%$ and $29 \%$, respectively, when cell temperatures were increased from $23^{\circ} \mathrm{C}$ to $65^{\circ} \mathrm{C}$.

These results mean that the reflectance can be tuned by adjusting cell temperature. Moreover, the color pigments have unique visible spectra, which is a key factor when considering multicolor activation of a reflective fine gray level. For a TCD cell size of $2.2 \times 1.4 \mathrm{~cm}^{2}$, the current required to generate maximum color reflectance was 0.16 $\mathrm{A}$ at $6 \mathrm{~V}$, which corresponded to a power requirement of $1 \mathrm{~W}$ at a cell temperature of $65^{\circ} \mathrm{C}$.

To investigate the potential of TCD cells for flexible information displays where high pixel resolution is not demanded, we simply examined optical and mechanical cell stabilities. The TCD cell was bent by using hand power. Figure 4 shows photographs of a bent thermochromic display and reflectance spectra of the green cell exposed to repeated bending under no applied voltage $\left(23^{\circ} \mathrm{C}\right)$ and under an applied voltage of $6 \mathrm{~V}\left(65^{\circ} \mathrm{C}\right)$, and contrast ratios (CR) according to polar angle at azimuthal angles of $0^{\circ}$, $45^{\circ}, 90^{\circ}$, and $135^{\circ}$. As shown in Fig. 4(a)-(b), the "RGB" logo was activated in a highly bent state and even reflectance at room temperature and at $65^{\circ} \mathrm{C}$ were almost unchanged after repeated bending (100 times), as shown in Fig. 4(c).

Based on Fig. 4(d)-(f), the CR values of the red, green, and blue pigments were $6.5: 1,7.3: 1$, and 7:1, respectively, in almost all directions for polar angles above $80^{\circ}$, which we ascribe to an excellent viewing angle, which provided almost the same image quality over $80^{\circ}$ without any additional optical components. Moreover, the maximum CR of the TCD cell at $6 \mathrm{~V}\left(65^{\circ} \mathrm{C}\right)$ was $7.5: 1$, which is much larger than the $\mathrm{CR}$ value $(2.87: 1)$ of the polydiacetylene-based display reported by $\mathrm{O}$. Yarimaga et al. [12]. When a voltage above $6 \mathrm{~V}$ was applied, the image appeared within 2 s. However, recovery (turn-off time) took $10 \mathrm{~s}$ at room temperature. We believe that the proposed TCD cell has great potential for poster information display applications because of its simplicity and cost effectiveness, even though it has a slow response time. 


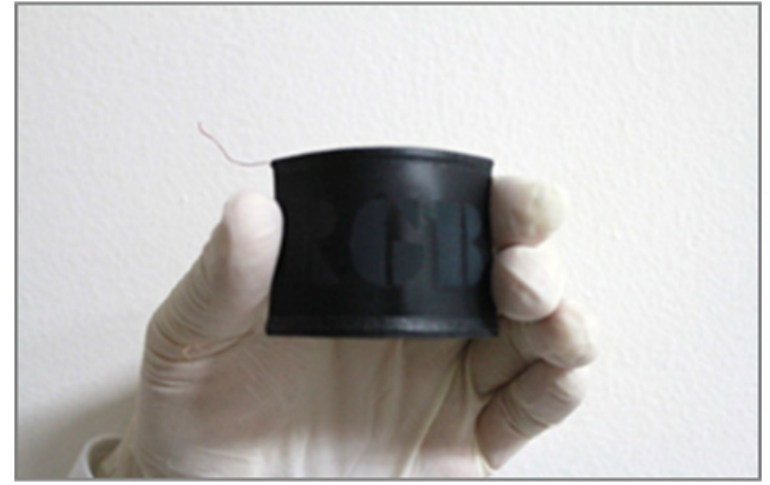

(a)

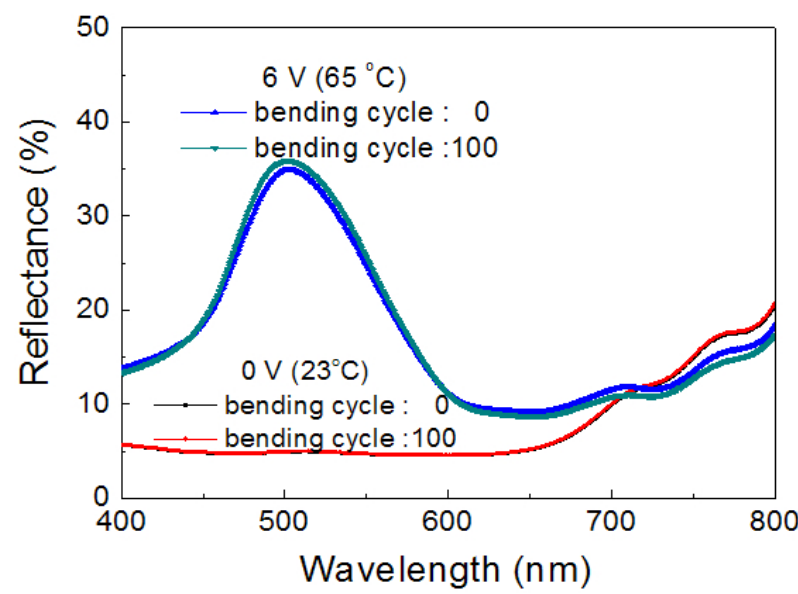

(c)

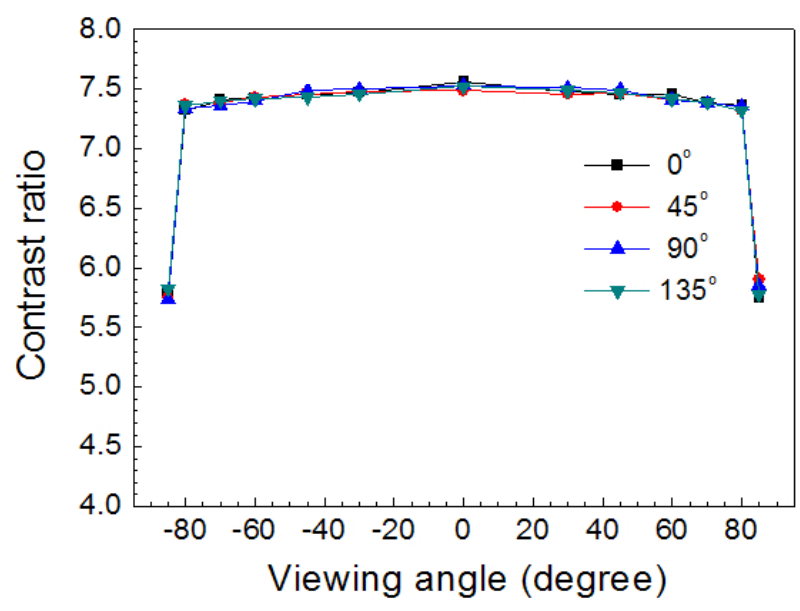

(e) Green color

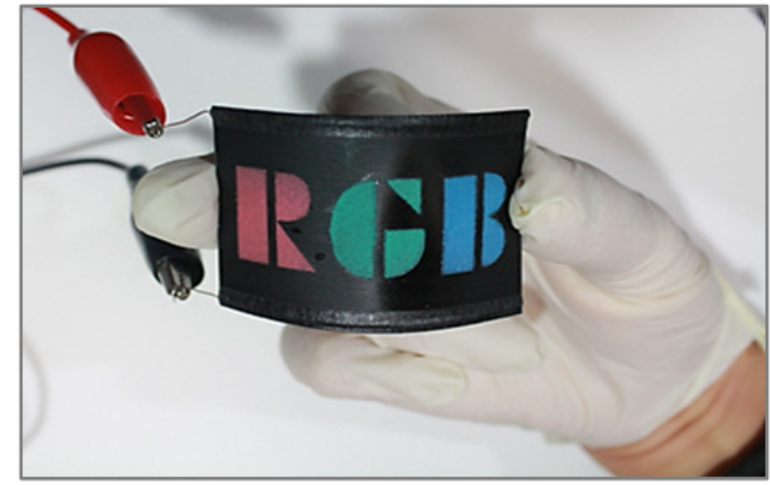

(b)

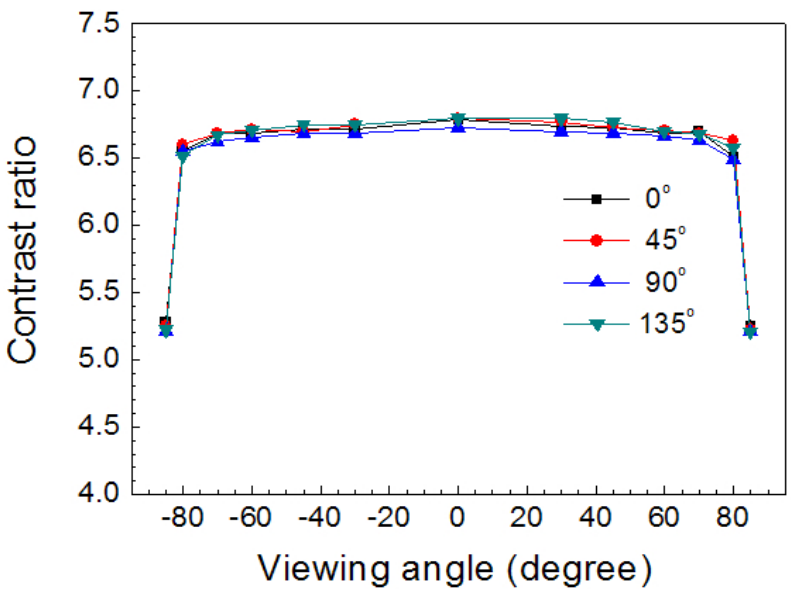

(d) Red color

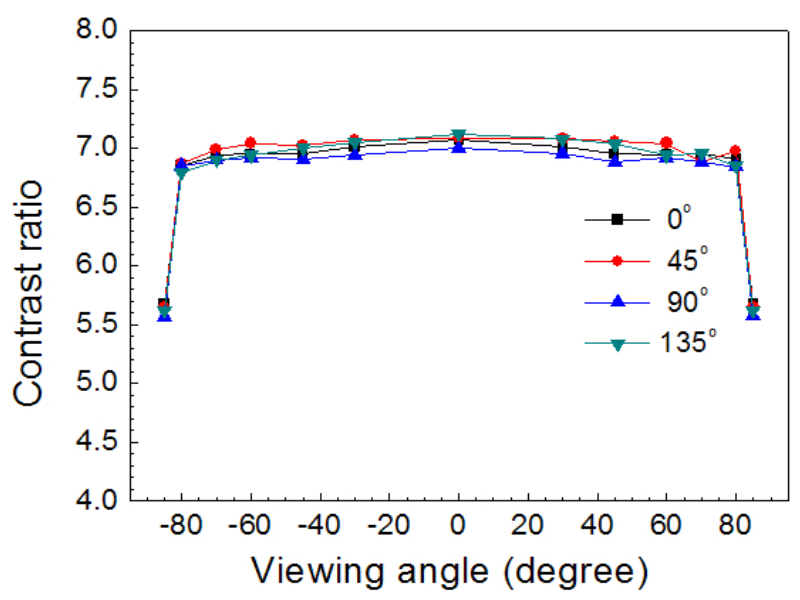

(f) Blue color

FIG. 4. Photo images of the bent thermochromic display cell with a "RGB" logo: (a) the off state ( 0 V) and (b) in the steady state under an applied voltage of $6 \mathrm{~V}$, (c) Reflectance spectra at room temperature and at $65{ }^{\circ} \mathrm{C}$ of a thermochromic display cell after repetitive bending, and contrast ratio characteristics by polar angle at each azimuthal angle for (d) red, (d) green, and (e) blue thermochromic pigments.

\section{CONCLUSION}

We present a flexible reflective TCD comprised of thermochromic pigments on an ITO-sputtered polyethylene naphthalate (PEN) film. The described TCD was fabricated by spraying, which is simple and cost effective. In addition, multicolor activation was well maintained even in a highly bent state, had a wide viewing angle of over $80^{\circ}$, and its thermooptical performance was stable under mechanical bending stress. Although this device is not ideal for general 
application, we believe that it will find a niche in the outdoor information display sector, which demands costeffectiveness, lightness, and ease of use, and that it will be of interest to those developing low-end e-paper and information applications.

\section{ACKNOWLEDGMENT}

This research was supported by Basic Science Research Program through the National Research Foundation of Korea(NRF) funded by the Ministry of Science, ICT and Future Planning(No. 2013R1A1A1A05006783) and the Human Resources Development Program (No. 20124030200100) of the Korea Institute of Energy Technology Evaluation and Planning (KETEP) grant funded by the Korea government Ministry of Trade, Industry and Energy.

\section{REFERENCES}

1. H. Sato, H. Fujikae, H. Kikuchi, and T. Kurita, "Bending tolerance of ferroelectric liquid crystal with polymer walls fastening plastic substrates," Jpn. J. Appl. Phys. Part 2 42, L476-L478 (2003).

2. H. Sato, H. Fujikae, Y. Iino, M. Kawakita, and H. Kikuchi, "Flexible grayscale ferroelectric liquid crystal device containing polymer walls and networks," Jpn. J. Appl. Phys. Part 1 41, 5302-5306 (2002).

3. D.-W. Kim, C.-J. Yu, Y.-W. Lim, J.-H. Na, and S.-D. Lee, "Mechanical stability of a flexible ferroelectric liquid crystal display with a periodic array of columnar spacers," Appl. Phys. Lett. 87, 051917-1 05917-3 (2005).

4. A. Henzen, N. Ailenei, F. V.Reeth, G. Vansichem, R. W. Zehner, and K. Amundson, "An electronic ink low latency drawing tablet," in Proc. SID Int. Symp. Digest Tech. Papers (Washington State Convention and Trade Center, Seattle, Washington, USA, 2004), vol. 35, pp. 1070-1073.

5. L. Liu, S. Pen, W. Wen, and P. Sheng, "Paperlike thermo- chromic display," Appl. Phys. Lett. 90, 213508-1 213508-3 (2007).

6. H. A. Seeboth, J. Kriwanek, and R. Vetter, "Novel chromogenic polymer gel networks for hybrid transparency and color control with temperature," Adv. Mater. (Weinheim, Ger.) 12, 1424-1426 (2000).

7. Y. Noguchi, T. Sekitani, and T. Someya, "Organic-transistorbased flexible pressure sensors using ink-jet-printed electrodes and gate dielectric layers," Appl. Phys. Lett. 89, 253507-1 253507-3 (2006).

8. O. Yarimaga, M. Im, B. Gu, T. W. Kim, Y. K. Jung, H. G. Park, and Y. K. Choi, "A thermally actuated organic display device using thermo-chromatic polymer composite film with self-aligned patterns," in Proc. IEEE MEMS Technical Digest (Tucson, Arizona, USA, 2008), pp. 750-753.

9. M. Seredyuk, A. B. Gaspar, V. Ksenofontov, S. Reiman, Y. Galyametdinov, W. Haase, R. Vetter, and P. Gutlich, "Room temperature operational thermochromic liquid crystals," Chem. Mater. 18, 2513-2519 (2006).

10. A. Mills and A. Lepre, "Development of novel thermochromic plastic films for optical temperature sensing," Analyst (Cambridge, UK) 124, 685-689 (1999).

11. M. G. Baron, M. Elie, M. G. Baron, and M. Elie, "Temperature sensing using reversible thermochromic polymeric films," Sens. Actuators B Chem. 90, 271-275 (2003).

12. O. Yarimaga, M. Im, Y.-K. Choi, T. W. Kim, Y. K. Jung, H. G. Park, S. Lee, and J.-M. Kim, "A color display system based on thermochromic conjugated polydiacetylene superamolecules," Macromol. Res. 18, 404-407 (2010).

13. A. Seeboth, R. Ruhmann, and O. Mühling, "Thermotropic and thermochromic polymer based materials for adaptive solar control," Materials 3, 5143-5168 (2010).

14. K. C. Heo, Y. Sohn, J. Yi, J. H. Kwon, P. K. Son, and J. S. Gwag, "Reflective color display using thermochromic pigments," Appl. Opt. 51, 4246-4249 (2012).

15. http://www.hwsands.com/category/141.aspx.

16. D. C. Maclaren and M. A. White, "Design rules for reversible thermochromic mixtures," J. Mater. Chem. 40, 669-676 (2005).

17. G. Shimizu, Shiga, and Y. Hayasshi, "Thermochromic composition," U. S. Patent, US4717710 (5 January 1998). 